\title{
Crack paths in multiaxial fatigue of C45 steel specimens and correlation of lifetime with the thermal energy dissipation
}

\author{
D. Rigon \\ Department of Industrial Engineering, University of Padova, Padova, Italy \\ daniele.rigon@unipd.it
}

\section{F. Berto}

Department of Mechanical and Industrial Engineering, Norwegian University of Science and Technology, Trondheim, Norway filippo.berto@ntnu.no

\author{
G. Meneghetti \\ Department of Industrial Engineering, University of Padova, Padova, Italy \\ giovanni.meneghetti@unipd.it
}

\begin{abstract}
The work reports the observed fatigue damage of C45 steel specimens tested in a previous work under multiaxial loading conditions and its relationship with the thermal energy dissipation which has been used in the last decades to estimate the uniaxial fatigue behavior of metals. For this purpose, fatigue data relevant to thin-walled samples made of quenched and tempered C45 steel tested under completely reversed combined axial and torsional cyclic loadings with different biaxiality ratios and phase-shift angles have been analysed. The analyses of crack paths at the initiation point of failure were performed after a 50\% stiffness loss that corresponded to a crack size ranging from 7 to $15 \mathrm{~mm}$; afterwards, the characteristic crack paths of each loading condition were analysed by using a digital microscope to identify the orientation of the crack initiation plane. After having broken all fatigue tested specimens under static tensile loading, the fracture surfaces were inspected close to the crack initiation point using a digital microscope. Despite the stress states and fatigue damage mechanisms dependent on the load condition, the $\mathrm{Q}$ parameter applied to the present experimental results proved to correlate all multiaxial fatigue test results in a single fatigue scatter band.
\end{abstract}

KEYWORDS. Multiaxial fatigue damage; Crack paths; Energy method; Specific heat loss.

\section{OPEN ACCESS}

Citation: Rigon, D., Berto, F., Meneghetti, G.,, Crack paths in multiaxial fatigue of $\mathrm{C} 45$ steel specimens and correlation of lifetime with the thermal energy dissipation, Frattura ed Integrità Strutturale, 59 (2022) 525-536.

Received: 08.11.2021

Accepted: 16.12 .2021

Published: 01.01.2022

Copyright: (c) 2022 This is an open access article under the terms of the CC-BY 4.0, which permits unrestricted use, distribution, and reproduction in any medium, provided the original author and source are credited. 


\section{INTRODUCTION}

$\mathrm{M}$ ultiaxial fatigue approaches available in the literature are based on strain, stress, or energy quantities. In the case of plain or bluntly notched components, the damage parameters are evaluated at the most stressed points, while they are averaged in the surrounding of the notch tip in the presence of sharp notches. The reader can refer to [1-3] for a comprehensive review of multiaxial stress, strain, or energy-based fatigue approaches. Among the different damage quantities adopted in multiaxial fatigue analysis, this paper deals with an experimental energy-based approach.

Energy combines stresses and strains and it has been adopted as a damage parameter in theoretical or experimental approaches. Regarding the energy parameter involved in the fatigue damage of metallic materials, Ellyin [4] argued that of the total energy expended in a unit volume of material, only part is stored in the form of internal energy, while a part is dissipated as heat, which induces some temperature increase during fatigue testing. Ellyin [4] noted that the heat energy exchanges are clearly involved in fatigue experiments and occur with a certain temperature increase in the material. Indeed, the phenomenon of self-heating dates back to the paper by Stromeyer [5] and, more recently, has been exploited to rapidly estimate the fatigue limit [6-9].

Meneghetti [10] proposed to adopt the specific heat loss per cycle (i.e., the heat energy released to the surroundings by a unit volume of material per cycle, the $\bar{Q}$ parameter) as a fatigue damage index for the following reasons: first, the specific heat loss was demonstrated to be independent of the mechanical, thermal, and testing boundary condition in usual laboratory environment for fatigue testing and to be a material property for a given applied stress amplitude, mean stress and stress state; second, it can be measured indirectly starting from surface temperature arising during the fatigue tests. A comprehensive theoretical background behind this approach is reported in a previous paper [11].

To evaluate the specific heat loss, it can be applied the so-called cooling gradient technique immediately after a sudden test interruption of the cyclic loadings [10]. Such technique is convenient because (i) it does not require accurate control of the thermal boundary conditions during the fatigue tests, which therefore can be conducted in a standard laboratory environment, (ii) it considers all heat transfer mechanisms (i.e. conduction, convection and radiation) which are active during experiments, (iii) it estimates the specific heat loss at the point where the cooling gradient is measured, and it can be applied to plain specimens, notched specimens and geometrically complex components under multiaxial fatigue loading.
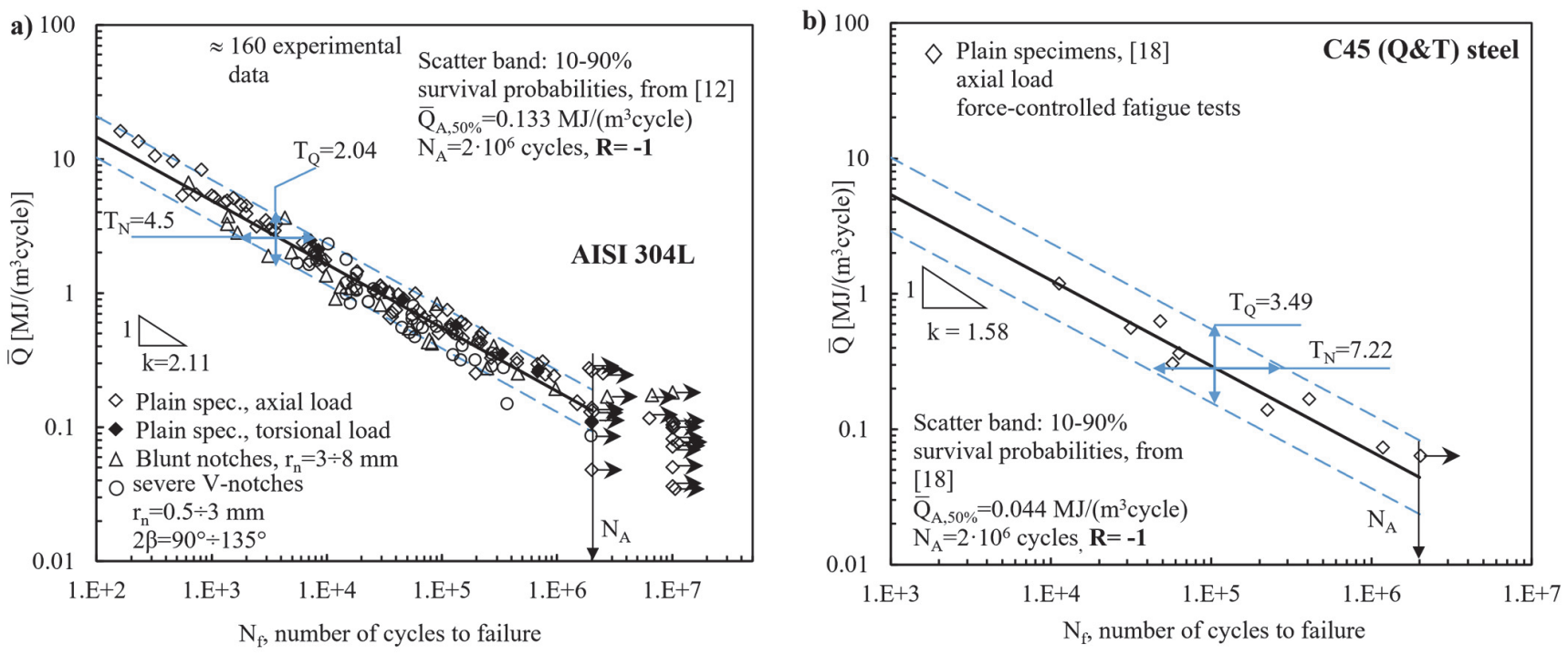

Figure 1: (a) $\cdot \bar{Q}-\mathrm{N}_{\mathrm{f}}$ summary of fully reversed pure axial fatigue tests obtained from plain, bluntly and severely notched specimens and pure torsion fatigue test results on plain specimens made of AISI 304L stainless steel [12-17]; (b) Fully reversed, axial fatigue test results expressed in terms of $\bar{Q}$ obtained on quenched and tempered, C45 plain steel specimens (from [18]).

By using the $\mathrm{Q}$ parameter, more than 140 uniaxial fatigue test results $(\mathrm{R}=-1)$ relevant to plain, bluntly and severely notched AISI 304L stainless steel specimens were rationalised in a single scatter band [12], (Fig.1(a)). The details of the fatigue tests are reported in [12-17]. The specific heat loss per cycle can be evaluated in situ during a fatigue test by means of Eqn.(1) [10]: 


$$
\bar{Q}=\frac{\left.\rho \cdot c \cdot \dot{T}\right|_{t=t^{*}}}{f_{L}}
$$

where $\rho$ is the material density, $\mathrm{c}$ is the material specific heat and $\mathrm{f}_{\mathrm{L}}$ is the load test frequency and $\dot{T}$ is the initial cooling gradient after having suddenly interrupted the fatigue test at the time $t^{*}$.

The case of multiaxial loading condition was the focus of a recently published paper by the authors [19], where an experimental campaign was conducted on quenched and tempered C45 steel specimens to validate the energy-based approach based on Eqn. (1) and to define a new energy-based master curve of such a material starting from a previously published fatigue scatter band fitted on uniaxial fatigue data only (Fig. 1b [18]). This paper extends the analyses of fatigue damage mechanisms involved in all previously tested multiaxial loading conditions [19] to support the use of the Q parameter under multiaxial loading conditions, at least for the investigated C45 steel material.

\section{MATERIALS AND METHODS}

$\mathrm{T}$

he specimens tested in [19] came from 25mm-diameter bars made of quenched and tempered medium carbon C45 steel (C45 Q\&T), characterized by a yield strength and tensile strength equal to $592 \mathrm{MPa}$ and $779 \mathrm{MPa}$, respectively. Thin-walled tubular specimens were machined according to the "hourglass" shape geometry reported in Fig. 2.

The density $\varrho$ and the specific heat $\mathrm{c}$ of the material were taken from Meneghetti et al. [18], namely $7850 \mathrm{~kg} / \mathrm{m}^{3}$ and 486 $\mathrm{J} /(\mathrm{kg} \mathrm{K})$, respectively.

The outer and inner surfaces of the specimens were polished using progressively finer emery paper starting from grade 400 to 1000 , which led to Ra values equal to $0.35 \pm 0.08 \mu \mathrm{m}$ and $0.45 \pm 0.06 \mu \mathrm{m}$ at the outer and inner surfaces, respectively.

The fatigue tests were carried out by using a servohydraulic MTS 809 axial/torsional test system controlled by an MTS FlexTest 40 digital controller and equipped with a load cell having $100 \mathrm{kN}$ axial load and $2000 \mathrm{Nm}$ torque capacities. Constant-amplitude cyclic axial and torsional loads were applied with load ratio $\mathrm{R}=-1$. In-phase $\left(\varphi=0^{\circ}\right)$ as well as out-ofphase $\left(\varphi=90^{\circ}\right)$ cyclic axial and torsion loads were applied adopting two different ratios between the applied axial and shear stress amplitude $\left(\Lambda=\sigma_{a} / \tau_{a}=1\right.$ and $\Lambda=\sqrt{ } 3$, respectively).

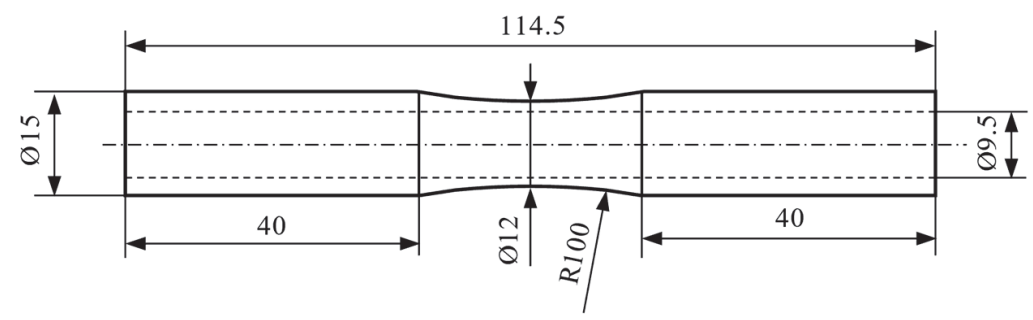

Figure 2: Specimen's geometry for multiaxial fatigue tests (units: [mm]).

In this paper, the shear stress amplitude, $\tau_{a}$, was calculated using the equation suggested by ASTM E2207 - 15 [20]:

$$
\tau_{\mathrm{a}}=\frac{16 \mathrm{M}_{\mathrm{t}, \mathrm{a}}}{\pi\left(\mathrm{d}_{\mathrm{e}}^{2}-\mathrm{d}_{\mathrm{i}}^{2}\right)\left(\mathrm{d}_{\mathrm{e}}+\mathrm{d}_{\mathrm{i}}\right)}
$$

that can be used for thin-walled specimens with the assumption that the shear stresses are uniformly distributed over the net-cross section. $\mathrm{M}_{\mathrm{t}, \mathrm{a}}, \mathrm{d}_{\mathrm{e}}$ and $\mathrm{d}_{\mathrm{i}}$ are the applied torque amplitude, the outer and inner diameters of the net- section, respectively. Although the shear stress distribution along the thickness of thin-walled specimens is dependent on the elasticplastic material properties [21], the accurate estimation of the shear stress due to torsional load is not strictly necessary in this work, because the final aim it to rationalize all fatigue data in terms of $\bar{Q}$.

The end of the tests was set at $50 \%$ stiffness loss and defined the number of cycles to failure $\mathrm{N}_{\mathrm{f}}$. This failure criterion implied the formation of through-the-thickness 7 to 15 -mm-long cracks. The relevant crack paths were observed on the outer surface of the specimen using a DINOLite ${ }^{\circledR}$ digital microscope. Afterwards, the specimens were broken under monotonic 
axial load in order to observe the fracture surfaces by using the same digital microscope and to identify the zone of crack initiation.

During the fatigue tests performed in [19], the surface temperature of the specimens was measured by means of an infrared camera TELOPS TS-IR-MW operating at a sampling rate of $50 \mathrm{~Hz}$. During each fatigue test, 2 to 15 sudden stops of the testing machine were performed to evaluate the $\bar{Q}$ using Eq 1 . For additional details on the testing procedure for evaluating $\bar{Q}$, the reader is referred to [19].
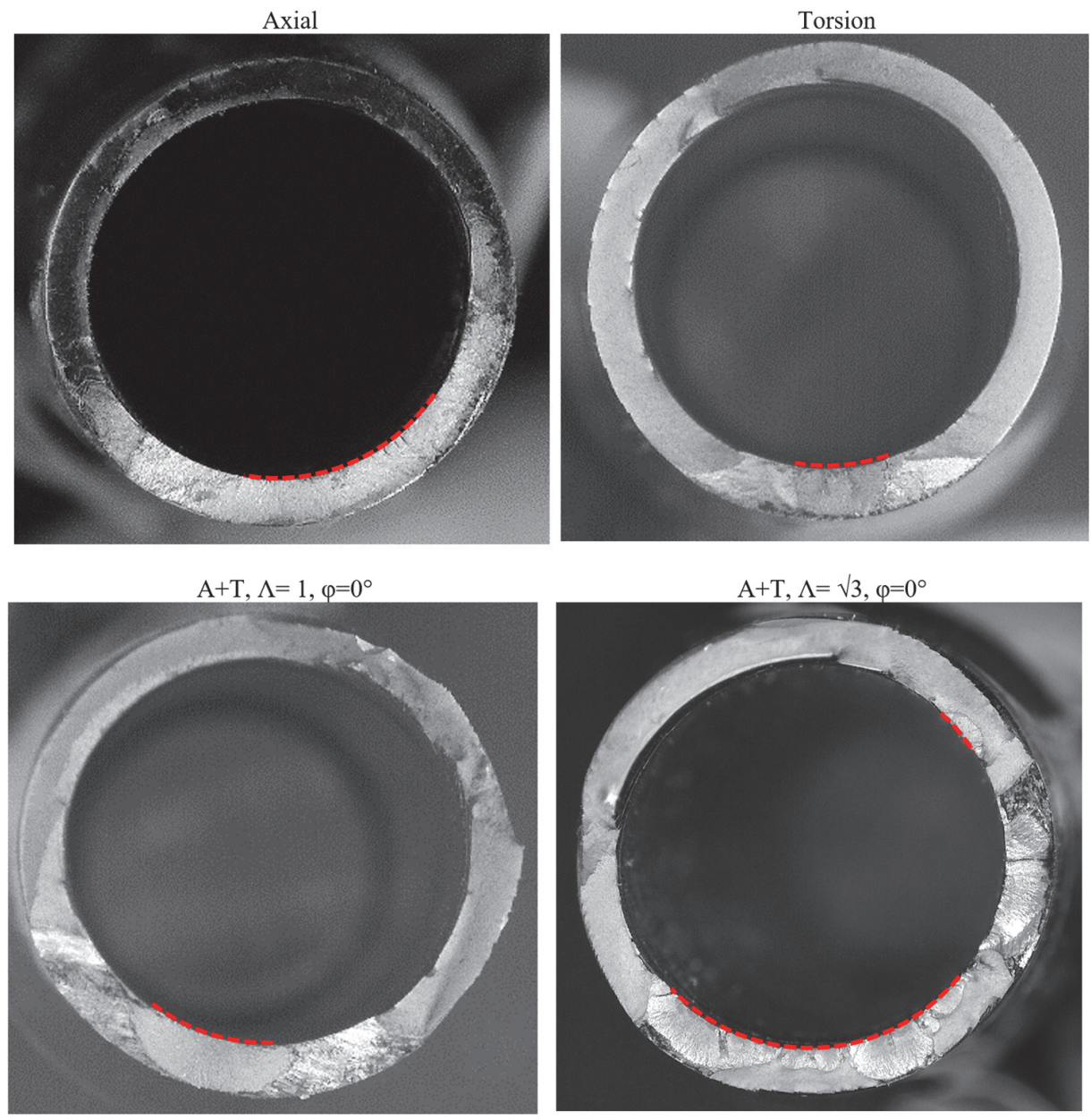

Figure 3: Selection of fracture surfaces observed after having broken the fatigue failed specimens (at $50 \%$ of stiffness loss). The dashed red lines highlight the crack initiation region.

\section{CRACK PATH ANALYSES}

A lmost all fatigue cracks initiated from the inner surface of the specimens as reported in the selection of fracture surfaces shown in Fig. 3, where the crack initiation areas are highlighted by dashed red lines. This experimental outcome is in agreement with the different roughness values measured on the inner and outer specimens' surfaces, the Ra roughness parameter being higher on the inner surface. However, even though the crack initiation occurred mainly on the inner surface, the orientation of the crack initiation plane remained constant through the thickness of the specimens, due to the reduced specimens' wall.

The extension of the crack on the outer surface at $50 \%$ stiffness loss ranged from approximately 7 to $15 \mathrm{~mm}$. Therefore, the crack path analyses were performed by taking several pictures by rotating the specimens around its axis and then merging them to produce the images reported in Figs. 4-8.

Fig. 4 shows two examples of crack paths relative to pure axial and pure torsional fatigue loads. Notably, the fracture planes in the axial condition were always normal to the maximum principal stress, as indicated by the red lines of each figure. The 
crack path of Fig. 4a represents the case of multiple crack initiation at the net cross-section of the specimen followed by coalescence in a single macro crack. Stage I, namely the early crack initiation, could not be observed due to the macroscopic analyses shown in Figs. 4a and 4b, therefore it was not possible to recognize the crack initiation on the plane of maximum shear stress range, according to the literature [22,23]. During stage II propagation, the crack path remains normal to maximum principal stress up to specimen failure (Figs.4a and $4 \mathrm{~b}$ ). On the contrary, specimens subjected to pure torsional fatigue loads started to fail on the plane of the maximum shear stress range, as reported in Figs. 4c and 4d. The following crack propagation phase developed in both mutual planes of the maximum shear stress range indicated by the red lines reported in Figs. 4c and 4d.

In the cases of multiaxial proportional loading (i.e. $\varphi=0^{\circ}$ ) almost all failures initiated on the plane of maximum shear stress range that changes orientation between approximately $100^{\circ}$ to $110^{\circ}$ for $\Lambda$ equal to 1 and $\sqrt{3}$, respectively (Fig. 5 and 6 ). Only in specimens subjected to low cycle fatigue with combined in-phase axial and torsional loads characterized by $\Lambda=1$ (Fig. $5 \mathrm{a}$ and $5 \mathrm{~b}$ ), the fracture paths at initiation and during propagation were oriented normal to the specimen's axis. Whereas, in the high cycle fatigue regime for the case $\Lambda=1$ (Fig. 5) after the initiation and initial propagation on the plane maximum shear stress range, the crack deviated on the plane normal to the applied axial load (i.e., specimen's axis). This different behaviour between the low- and high- cycle fatigue regimes was not observed in specimens subjected to in-phase axial and torsional loads with $\Lambda=\sqrt{ } 3$ (Fig. 6).

All specimens subjected to non-proportional multiaxial load cases (i.e. $\varphi=90^{\circ}$ ) exhibited crack initiation on the plane of maximum shear stress range that is represented by the red lines in Figs. 7 and 8. During propagation, the non-proportional loading condition with $\Lambda=1$ (Fig. 7) generated less tortuous fracture paths than those observed when $\Lambda=\sqrt{3}$ (Fig. 8). Rigorously speaking, the propagation paths of Fig. 7 deviate only slightly from the plane of maximum shear stress range during crack propagation, whereas the deviation increases in the last fraction of fatigue life. Fig. 8 shows that after initiation, the cracks propagated in a plane approximately oriented at $45^{\circ}$ until the last fraction of fatigue life when they deviated to the plane normal to the axial load. No differences in crack initiation planes were observed between low cycle and high cycle fatigue regimes in the fracture paths of Fig. 8 except for one specimen failed in the low cycle fatigue regimes and characterised by $\Lambda=\sqrt{ } 3$ (Fig. 8a) in which the fracture was mainly planar.

Finally, Tab. 1 reports the summary of the fatigue damage in terms of crack initiation plane and the fracture path for each loading condition.

a) Axial, $\mathrm{N}_{\mathrm{f}}=5.55 \cdot 10^{4}$ cycles

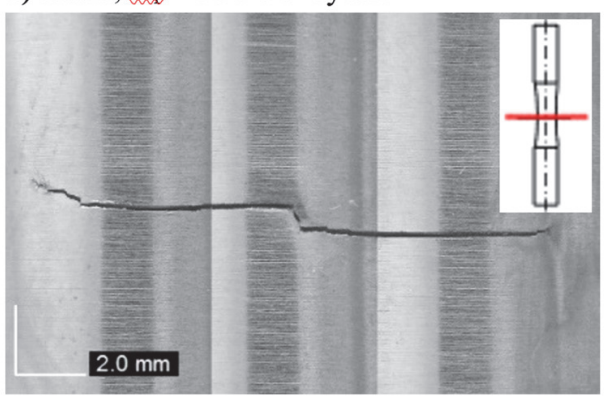

c) Torsion, $\mathrm{N}_{\mathrm{f}}=2.39 \cdot 10^{4}$ cycles

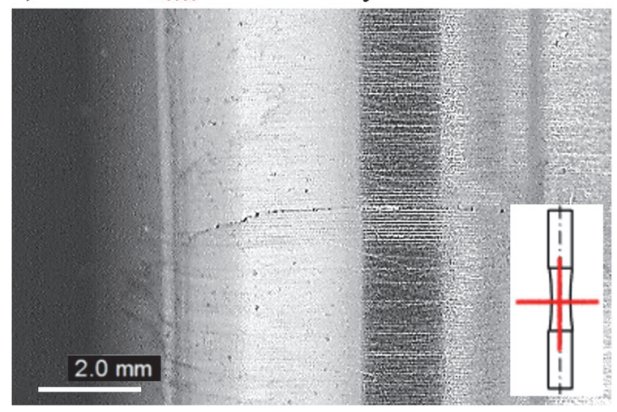

b) Axial, $\mathrm{N}_{\mathrm{f}}=3.88 \cdot 10^{5}$ cycles

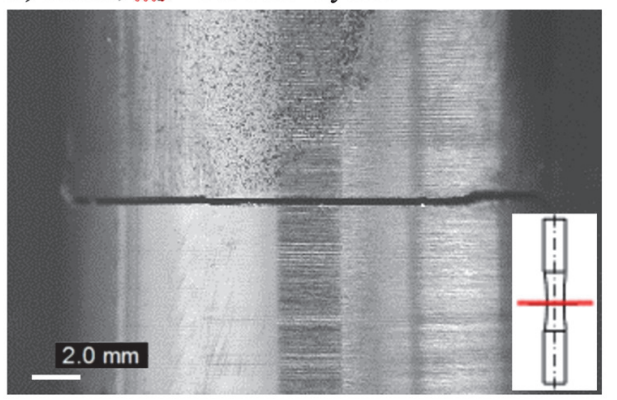

d) Torsion, $\mathrm{N}_{\mathrm{f}}=5.40 \cdot 10^{4}$ cycles

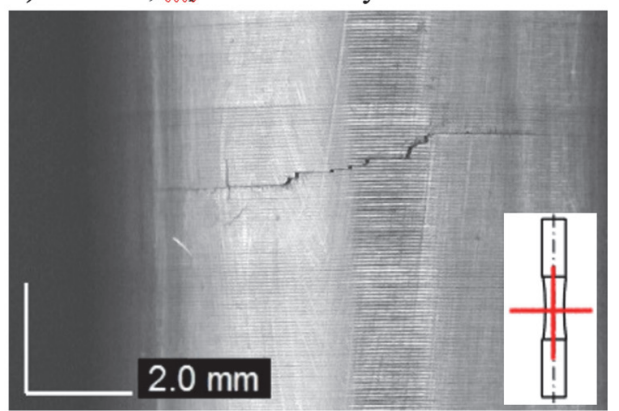

Figure 4: (a,b) Crack paths observed on the outer surface of the specimens for pure axial (c,d) and pure torsional loading condition. The red lines indicate the plane of maximum axial stress (in Fig. 4a, 4b) or the plane of the maximum shear stress range (in Fig. 4c, 4d). 
a) $\mathrm{A}+\mathrm{T}, \Lambda=1, \varphi=0^{\circ} \mathrm{N}_{\mathrm{f}}=5.63 \cdot 10^{3}$ cycles

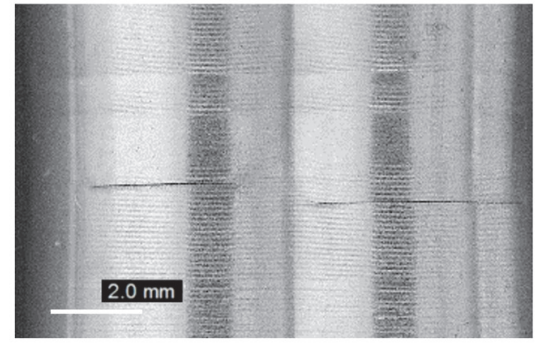

b) $\mathrm{A}+\mathrm{T}, \Lambda=1, \varphi=0^{\circ} \mathrm{N}_{\mathrm{f}}=7.69 \cdot 10^{3}$ cycles

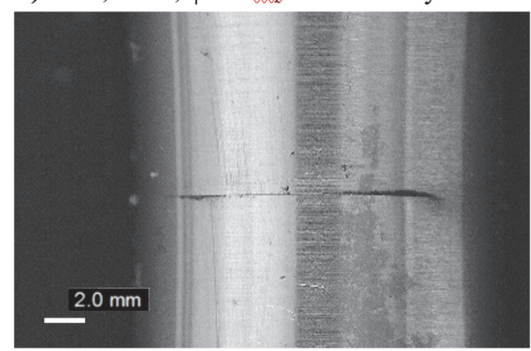

e) $\mathrm{A}+\mathrm{T}, \Lambda=1, \varphi=0^{\circ} \mathrm{N}_{\mathrm{f}}=4.27 \cdot 10^{5}$ cycles

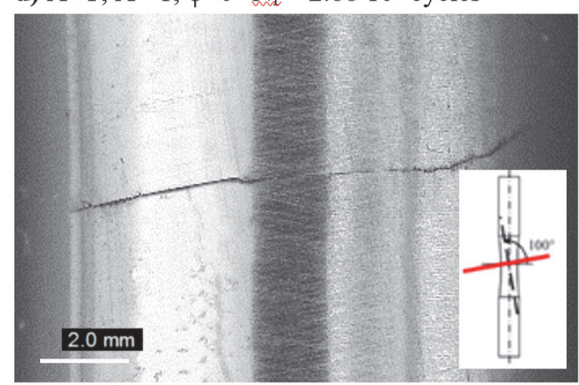

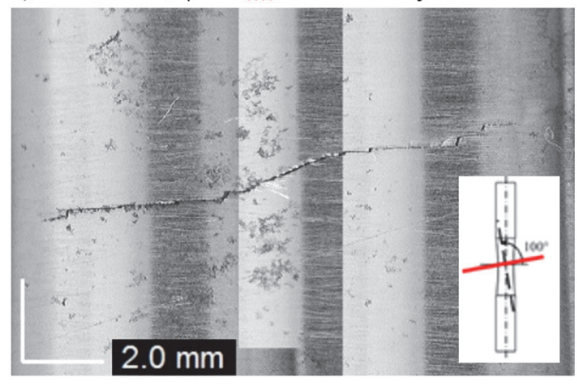

Figure 5: Crack paths observed on the outer surface of the specimen for $\Lambda=1$ in-phase loading condition. The red lines indicate the plane of maximum shear stress range.

a) $\mathrm{A}+\mathrm{T}, \Lambda=\sqrt{ } 3, \varphi=0^{\circ} \mathrm{N}_{\mathrm{f}}=4.09 \cdot 10^{3}$ cycles

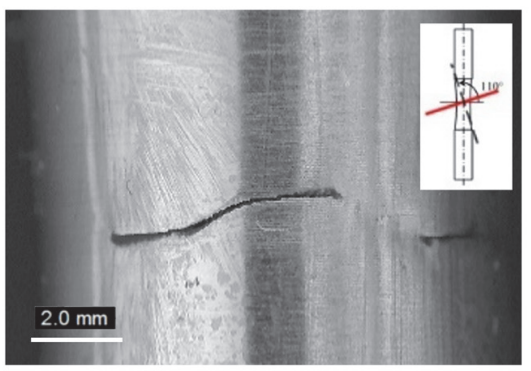

c) $\mathrm{A}+\mathrm{T}, \Lambda=\sqrt{3}, \varphi=0^{\circ} \mathrm{N}_{\mathrm{f}}=3.54 \cdot 10^{4}$ cycles

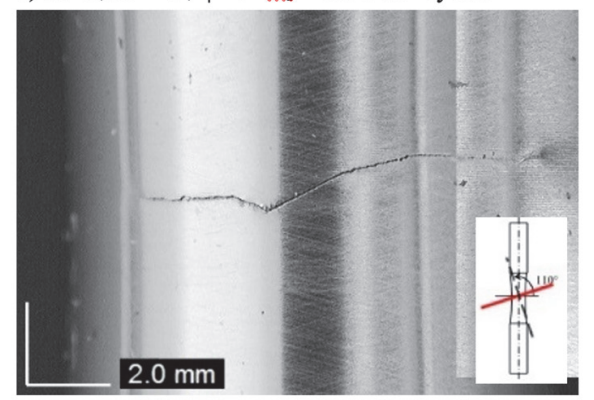

b) $\mathrm{A}+\mathrm{T}, \Lambda=\sqrt{ } 3, \varphi=0^{\circ} \mathrm{N}_{\mathrm{f}}=6.65 \cdot 10^{3}$ cycles

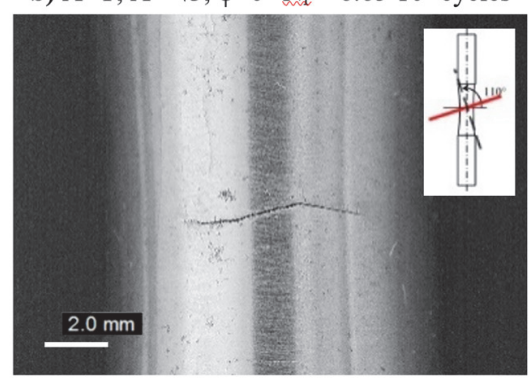

e) $\mathrm{A}+\mathrm{T}, \Lambda=\sqrt{ } 3, \varphi=0^{\circ} \mathrm{N}_{\mathrm{f}}=5.12 \cdot 10^{5}$ cycles

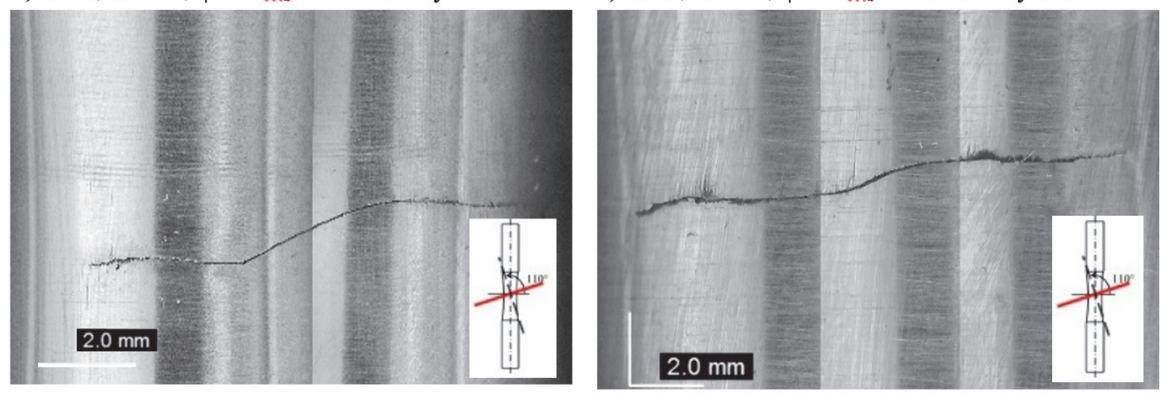

Figure 6: Crack paths observed on the outer surface of the specimen for $\Lambda=\sqrt{ } 3$ in-phase loading condition. The red lines indicate the plane of maximum shear stress range. 
a) $\mathrm{A}+\mathrm{T}, \Lambda=1, \varphi=90^{\circ} \mathrm{N}_{\mathrm{f}}=9.98 \cdot 10^{3}$ cycles

b) $\mathrm{A}+\mathrm{T}, \Lambda=1, \varphi=90^{\circ} \mathrm{N}_{\mathrm{f}}=1.04 \cdot 10^{4}$ cycles
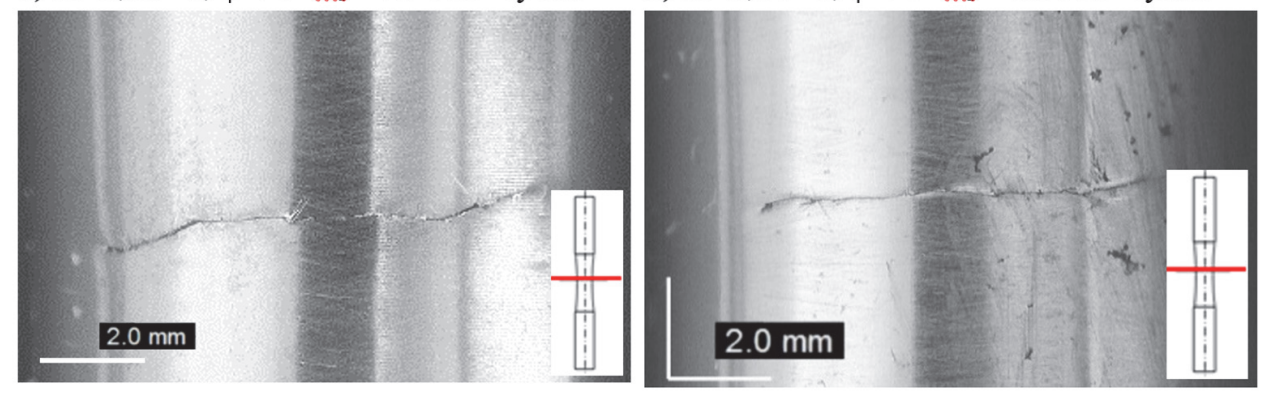

c) $\mathrm{A}+\mathrm{T}, \Lambda=1, \varphi=90^{\circ} \mathrm{N}_{\mathrm{k}}=5.19 \cdot 10^{4}$ cycles

d) $\mathrm{A}+\mathrm{T}, \Lambda=1, \varphi=90^{\circ} \mathrm{N}_{\mathrm{f}}=8.80 \cdot 10^{4}$ cycles
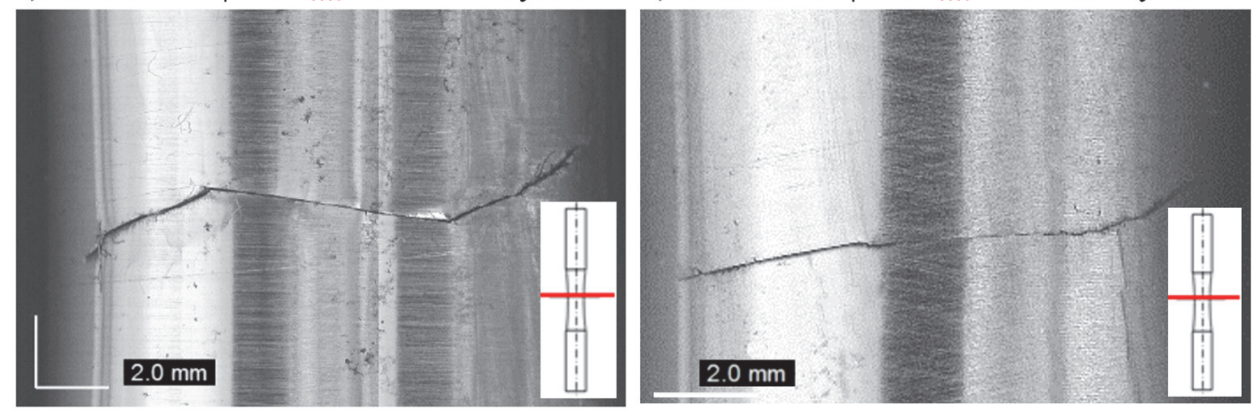

Figure 7: Crack paths observed on the outer surface of the specimen for $\Lambda=1$ out-of-phase loading condition. The red lines indicate the plane of maximum shear stress range.

a) $\mathrm{A}+\mathrm{T}, \Lambda=\sqrt{ } 3, \varphi=90^{\circ} \mathrm{N}_{\mathrm{f}}=8.03 \cdot 10^{3}$ cycles

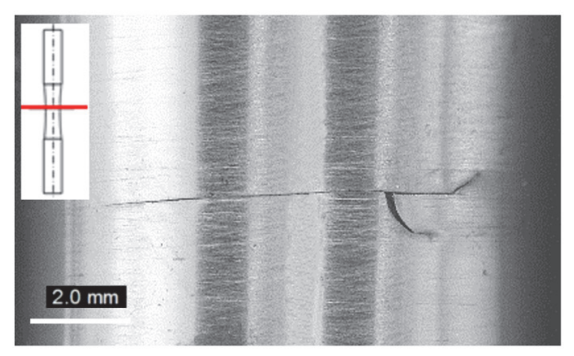

c) $\mathrm{A}+\mathrm{T}, \Lambda=\sqrt{ } 3, \varphi=90^{\circ} \mathrm{N}_{\mathrm{t}}=3.44 \cdot 10^{4}$ cycles

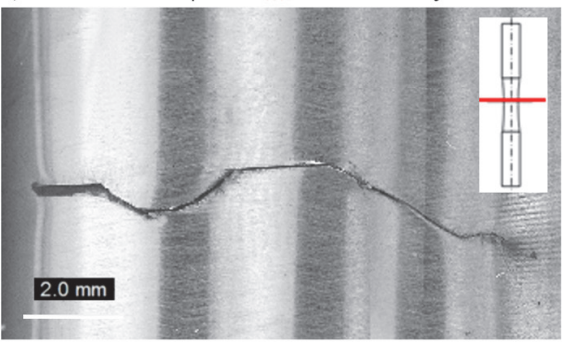

d) $\mathrm{A}+\mathrm{T}, \Lambda=\sqrt{3}, \varphi=90^{\circ} \mathrm{N}_{\mathrm{f}}=8.60 \cdot 10^{4}$ cycles

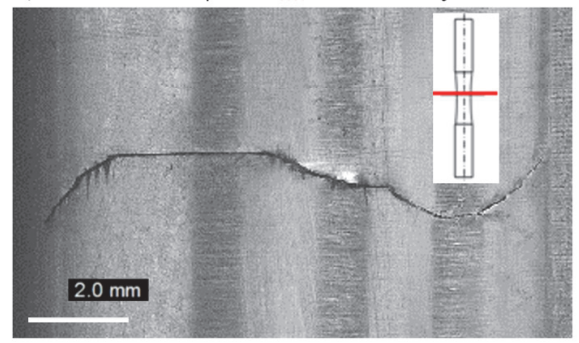

b) $\mathrm{A}+\mathrm{T}, \Lambda=\sqrt{3}, \varphi=90^{\circ} \mathrm{N}_{\mathrm{f}}=1.18 \cdot 10^{4}$ cycles

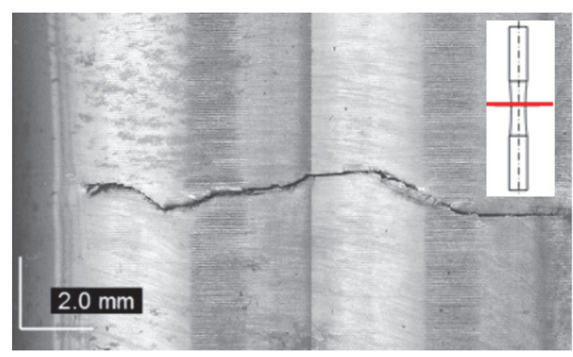

e) $\mathrm{A}+\mathrm{T}, \Lambda=\sqrt{ } 3, \varphi=90^{\circ} \mathrm{N}_{\mathrm{f}}=8.44 \cdot 10^{5}$ cycles

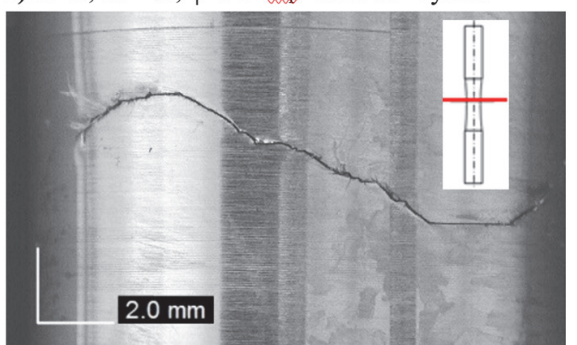

Figure 8: Crack paths observed on the outer surface of the specimen for $\Lambda=\sqrt{ } 3$ in-phase loading condition. The red lines indicate the plane of maximum shear stress range. 


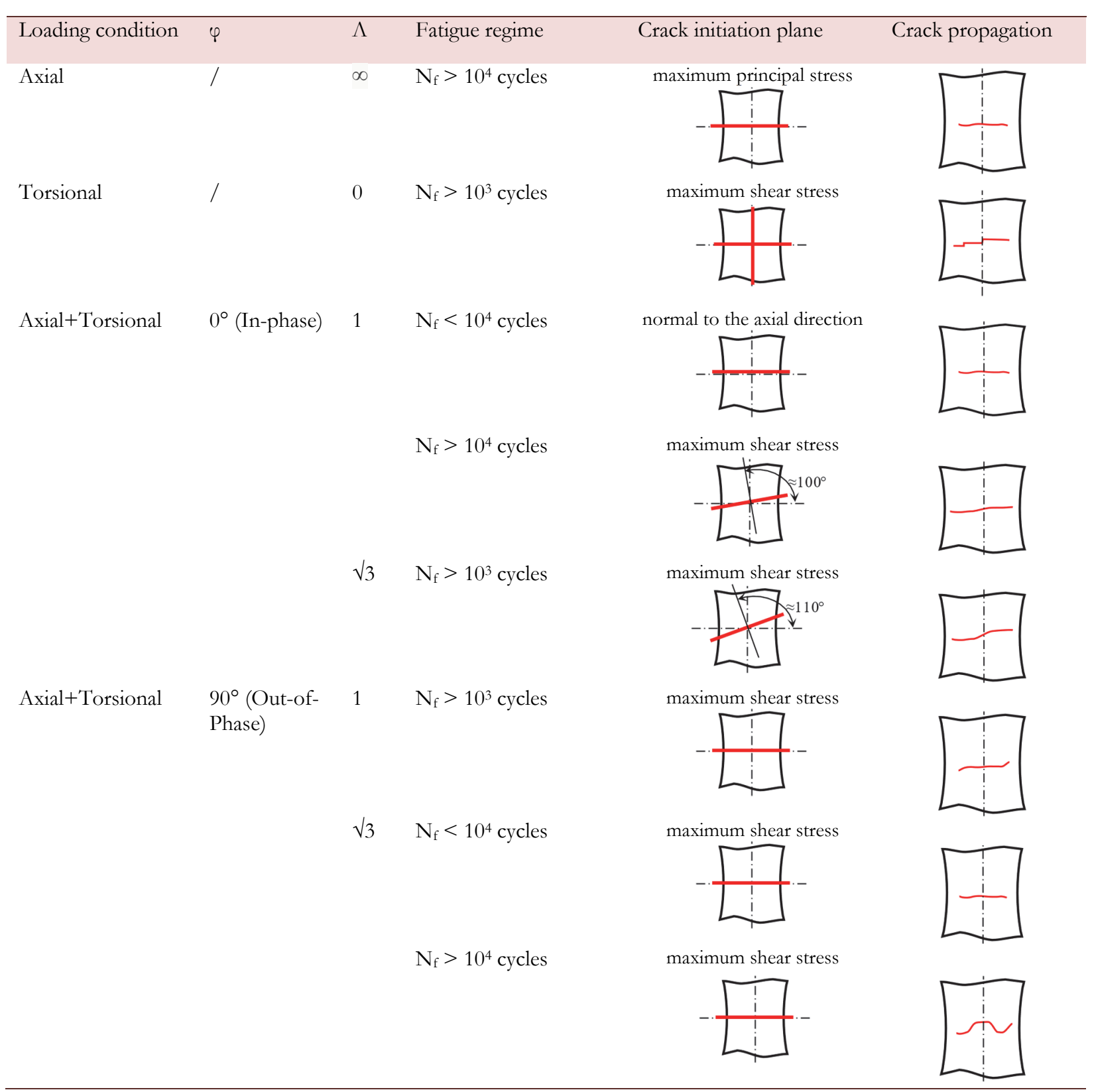

Table 1: Summary of crack path analysis for each loading condition analysed in this paper.

\section{ANALYSES OF THE SPECIFIC HEAT LOSS PER CYCLE DURING MULTIAXIAL FATIGUE TESTS}

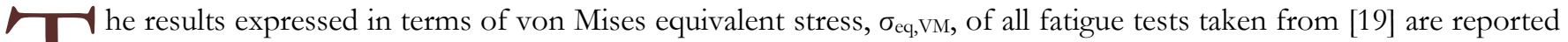
in Fig. 9 compared with experimental results obtained in a previous work on axial fatigue of the same material [18]. The figure shows that von Mises equivalent stress correlates axial and torsional fatigue data, but it does not correlate the fatigue data relevant to the multiaxial loading condition. Nevertheless, the scatter reported in Fig. 9 provides conservative estimations of the multiaxial fatigue strength for this material.

By presenting the same fatigue data in terms of energy parameter $\bar{Q}$ estimated by means of Eqn. (1), it has been proved that all experimental data collapse in a restricted scatter band characterized by a fatigue life scatter index $\mathrm{T}_{\mathrm{N}}=N_{10 \%} / N_{90 \%}$ $=5.02$, which is comparable with that relevant to uniaxial fatigue data only [19]. This experimental outcome supports the idea that $\bar{Q}$ seems to capture efficiently the effect of damage mechanisms that occur in different critical planes depending 
on the loading condition. To discuss in more detail this concept, Fig. 10a reports two examples of $\bar{Q}$ evolution during multiaxial fatigue tests with for $\Lambda=1$ and the same applied load level $\left(\sigma_{\mathrm{a}}=240 \mathrm{MPa} \tau_{\mathrm{a}}=240 \mathrm{MPa}\right)$ but different phase shift angles. Indeed, for this material, the in-phase loading condition was seen to be more damaging than the out-of-phase one and coherently the $\bar{Q}$ values are higher in the first case. The same can be observed in the two examples for $\Lambda=\sqrt{ } 3$, reported in Fig. 10b.

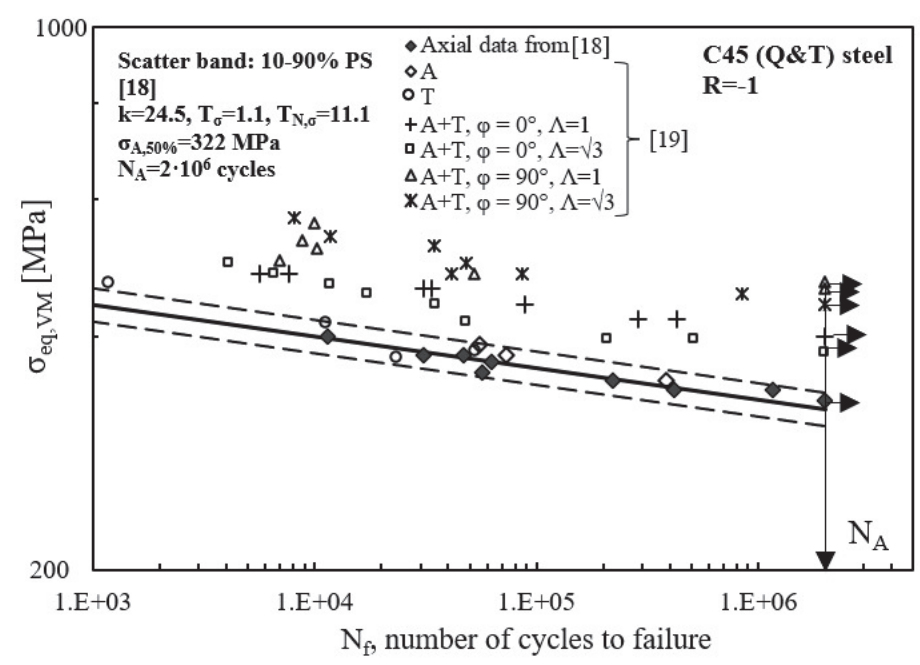

Figure 9: Fatigue test results using von Mises equivalent stress amplitude (data taken from [19]); additional axial fatigue test data with the relevant scatter band obtained previously are reported for comparison (data and scatter band from [18]).
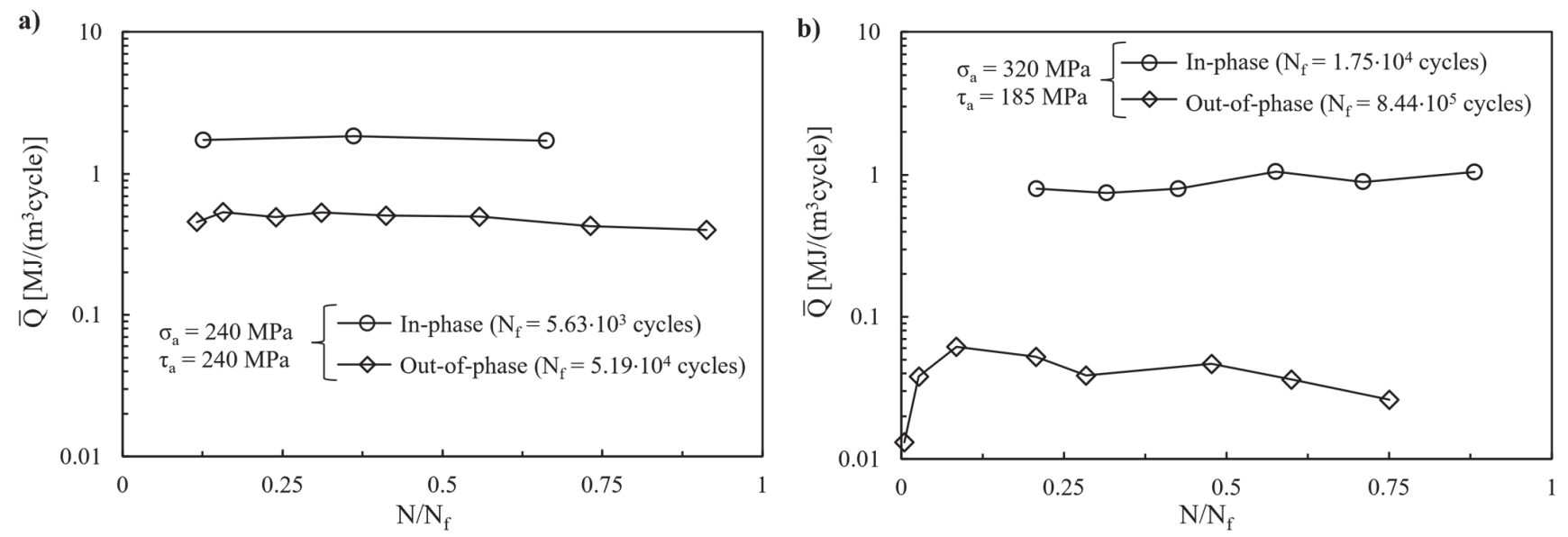

Figure 10: (a) Specific heat loss evolution of in-phase and out-of-phase multiaxial fatigue tests with $\Lambda=1$ and same applied stress amplitude. (b) Specific heat loss evolution of in-phase and out-of-phase multiaxial fatigue tests with $\Lambda=\sqrt{ } 3$ and same applied stress amplitude (data taken from [19]).

The goodness of the fatigue life estimation can be appreciated in Fig. 11, where all experimental fatigue life values available from [19] are reported against the estimated fatigue life by using the $\bar{Q}$-based fatigue model reported in [19].

To conclude, in the last decade, it was proved that for the stainless steel and carbon steel materials involved in the investigations, the specific heat loss measured at $50 \%$ of the fatigue life correlates the fatigue test results generated under several fully reversed loading conditions (such as axial, torsional and in-phase as well as out-of-phase combined axial/torsional) applied to plain specimens and under uniaxial fatigue loading applied to notched specimens with minimum notch tip radius equal to $0.5 \mathrm{~mm}$. While a two-parameter formulation of the approach to take into account the mean stress effect on pure axial loading condition was proposed recently [18], the mean stress effect under torsional and multiaxial cyclic loads together with the notch effect by using the $\bar{Q}$ parameter deserves to be investigated in future works. 


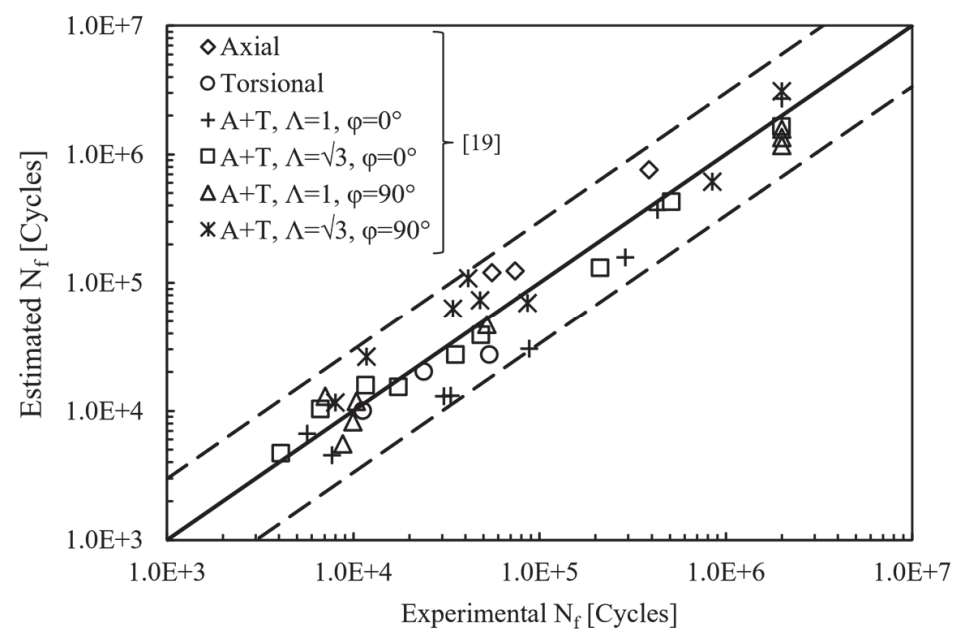

Figure 11: Comparisons between the experimental fatigue life of test results taken from [19] with the estimated number of cycles to failure from the $\bar{Q}$-based fatigue curve proposed in [19].

\section{CONCLUSIONS}

$\mathrm{I}$ n-phase and $90^{\circ}$-out-of-phase, fully reversed, combined axial/torsional $\left(\Lambda=\sigma_{a} / \tau_{a}\right.$ equal to 1 or $\left.\sqrt{ } 3\right)$ multiaxial fatigue test results previously published by the present authors and generated from $\mathrm{C} 45$ steel specimens have been analysed in order to investigate the fatigue damage mechanisms and the relationship of the experimental fatigue life with the measured specific heat loss. The main conclusions are the following:

- Two damage mechanisms were observed at the crack initiation phase in the fatigue tests: i) in the case of axial cyclic load, the cracks initiated on the plane normal to the maximum principal stress; ii) in the case of torsional loads the specimens started to fail on the plane of maximum shear stress range; iii) all the multiaxial loading conditions experience fatigue crack initiation on the plane of maximum shear stress range; few specimens subjected to low cycle fatigue characterised by in-phase $\Lambda=1$ loading and out-phase $\Lambda=\sqrt{ } 3$ loading, exceptionally exhibited crack initiation on the plane normal to axial load;

- For the material and loading conditions investigated here, the $\mathrm{Q}$ parameter efficiently captures the effect of the fatigue damage under different stress states and provides lifetime estimations in agreement with the experimental results.

\section{NOMENCLATURE}

c material specific heat $[J /(\mathrm{kg} \cdot \mathrm{K})]$

$\mathrm{f}_{\text {acq }} \quad$ sampling rate of the infrared camera $[\mathrm{Hz}]$

$\mathrm{f}_{\mathrm{L}} \quad$ load test frequency $[\mathrm{Hz}]$

$k \quad$ inverse slope of the fatigue curve

$\mathrm{N}_{\mathrm{A}} \quad$ reference number of cycles [cycles]

$\mathrm{N}_{\mathrm{f}} \quad$ number of cycles to failure [cycles]

$\bar{Q} \quad$ heat energy exchanged by a unit volume of material per cycle (specific heat loss) $\left[\mathrm{J} /\left(\mathrm{m}^{3} \cdot \mathrm{cycle}\right)\right]$

$\bar{Q}_{A, 10 \%}, \bar{Q}_{A, 50 \%}, \bar{Q}_{A, 90 \%} \quad \bar{Q}$ evaluated at $\mathrm{N}_{\mathrm{A}}$ for $10 \%, 50 \%, 90 \%$ survival probability $\left.\mathrm{J} /\left(\mathrm{m}^{3} \cdot \mathrm{cycle}\right)\right]$

$\mathrm{r}_{\mathrm{n}} \quad$ notch tip radius $[\mathrm{mm}]$

$\mathrm{T}_{\mathrm{N}} \quad$ life-based scatter index of the $\bar{Q}-\mathrm{N}_{\mathrm{f}}$ curve $\left(\mathrm{T}_{\mathrm{N}}=N_{10 \%} / N_{90 \%}\right)$

$\mathrm{T}_{\mathrm{Q}} \quad$ energy-based scatter index of the $\bar{Q}-\mathrm{N}_{\mathrm{f}}$ curve $\left(\mathrm{T}_{\mathrm{Q}}=\bar{Q}_{A, 10 \%} / \bar{Q}_{A, 90 \%}\right)$

$\dot{T}$ material temperature gradient $\left[{ }^{\circ} \mathrm{C} / \mathrm{s}\right]$

$2 \beta \quad$ notch opening angle $\left[{ }^{\circ}\right]$

$\lambda \quad$ material thermal conductivity $[\mathrm{W} /(\mathrm{m} \cdot \mathrm{K})]$ 


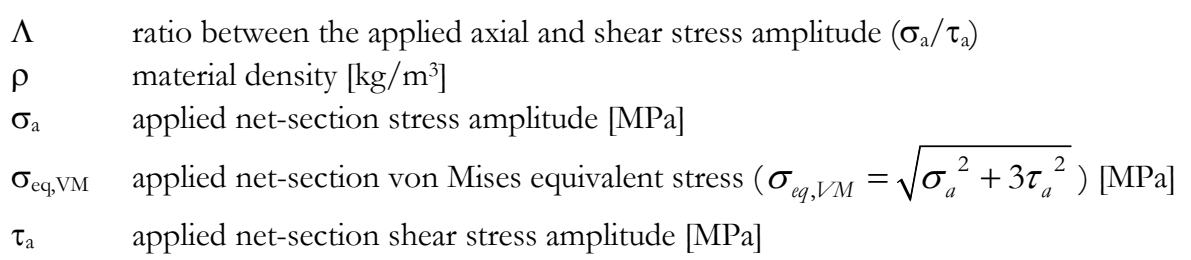

\section{REFERENCES}

[1] Socie, D.F., Marquis, G.B. (2000). Multiaxial fatigue, SAE International.

[2] Susmel, L. (2009). Multiaxial notch fatigue, Cambridge, Woodhead publishing.

[3] Radaj, D., Vormwald, M. (2013). Advanced Methods of Fatigue Assessment, Berlin, Heidelberg, Springer Berlin Heidelberg.

[4] Ellyin, F. (1997). Fatigue damage, crack growth, and life prediction, Chapman \& Hall.

[5] Stromeyer, C.E. (1914). The Determination of Fatigue Limits under Alternating Stress Conditions, Proc. R. Soc. A Math. Phys. Eng. Sci., 90(620), pp. 411-425, DOI: 10.1098/rspa.1914.0066.

[6] Curti, G., Geraci, A., Risitano, A. (1989). A new method for rapid determination of the fatigue limit (in italian), Ing. Automotoristica, 42, pp. 634-636.

[7] Luong, M.P. (1995). Infrared thermographic scanning of fatigue in metals, Nucl. Eng. Des., 158(2), pp. 363-376, DOI: $10.1016 / 0029-5493(95) 01043-H$.

[8] La Rosa, G., Risitano, A. (2000). Thermographic methodology for rapid determination of the fatigue limit of materials and mechanical components, Int. J. Fatigue, 22(1), pp. 65-73, DOI: 10.1016/S0142-1123(99)00088-2.

[9] Curà, F., Curti, G., Sesana, R. (2005). A new iteration method for the thermographic determination of fatigue limit in steels, Int. J. Fatigue, 27(4), pp. 453-459, DOI: 10.1016/j.ijfatigue.2003.12.009.

[10] Meneghetti, G. (2007). Analysis of the fatigue strength of a stainless steel based on the energy dissipation, Int. J. Fatigue, 29(1), pp. 81-94, DOI: 10.1016/j.ijfatigue.2006.02.043.

[11] Meneghetti, G., Ricotta, M. (2018). The heat energy dissipated in the material structural volume to correlate the fatigue crack growth rate in stainless steel specimens, Int. J. Fatigue, 115(July), pp. 107-119, DOI: 10.1016/j.ijfatigue.2018.07.037.

[12] Meneghetti, G., Ricotta, M., Atzori, B. (2013). A synthesis of the push-pull fatigue behaviour of plain and notched stainless steel specimens by using the specific heat loss, Fatigue Fract. Eng. Mater. Struct., 36(12), pp. 1306-1322, DOI: $10.1111 /$ ffe.12071.

[13] Meneghetti, G., Ricotta, M. (2012). The use of the specific heat loss to analyse the low- and high-cycle fatigue behaviour of plain and notched specimens made of a stainless steel, Eng. Fract. Mech., 81, pp. 2-16, DOI: $10.1016 /$ j.engfracmech.2011.06.010.

[14] Meneghetti, G., Ricotta, M., Negrisolo, L., Atzori, B. (2013). A Synthesis of the Fatigue Behavior of Stainless Steel Bars under Fully Reversed Axial or Torsion Loading by Using the Specific Heat Loss, Key Eng. Mater., 577-578, pp. 453456, DOI: 10.4028/www.scientific.net/KEM.577-578.453.

[15] Meneghetti, G., Ricotta, M. (2016). Experimental estimation of the heat energy dissipated in a volume surrounding the tip of a fatigue crack, Fract. Struct. Integr., 10(35), pp. 172-181, DOI: 10.3221/IGF-ESIS.35.20.

[16] Meneghetti, G., Ricotta, M., Rigon, D. (2017). The heat energy dissipated in a control volume to correlate the fatigue strength of severely notched and cracked stainless steel specimens. Fatigue 2017, Cambridge, UK.

[17] Rigon, D., Ricotta, M., Meneghetti, G. (2017). An analysis of the specific heat loss at the tip of severely notched stainless steel specimens to correlate the fatigue strength, Theor. Appl. Fract. Mech., 92, pp. 240-251, DOI: $10.1016 /$ j.tafmec.2017.09.003.

[18] Meneghetti, G., Ricotta, M., Atzori, B. (2016). A two-parameter, heat energy-based approach to analyse the mean stress influence on axial fatigue behaviour of plain steel specimens, Int. J. Fatigue, 82, pp. 60-70, DOI: 10.1016/j.ijfatigue.2015.07.028.

[19] Rigon, D., Berto, F., Meneghetti, G. (2021). Estimating the multiaxial fatigue behaviour of C45 steel specimens by using the energy dissipation, Int. J. Fatigue, 151, pp. 106381, DOI: 10.1016/j.ijfatigue.2021.106381.

[20] (2018). ASTM E2207 - 15. Standard Practice for Strain-Controlled Axial-Torsional Fatigue Testing with Thin-Walled Tubular Specimens, DOI: 10.1520/E2207-15.2.

[21] Seyda, J., Pejkowski, Ł., Skibicki, D. (2020). The Shear Stress Determination in Tubular Specimens under Torsion in 
the Elastic-Plastic Strain Range from the Perspective of Fatigue Analysis, Materials (Basel)., 13(23), pp. 5583, DOI: $10.3390 / \mathrm{ma1} 235583$.

[22] Hua, C.T., Socie, D.F. (1985). Fatigue damage in 1045 steel under variable amplitude biaxial loading, Fatigue Fract. Eng. Mater. Struct., 8(2), pp. 101-114, DOI: 10.1111/j.1460-2695.1985.tb01197.x.

[23] Fatemi, A., Socie, D.F. (1988). A critical plane approach to multiaxial fatigue damage including out-of-phase loading, Fatigue Fract. Eng. Mater. Struct., 11(3), pp. 149-165, DOI: 10.1111/j.1460-2695.1988.tb01169.x. 